\title{
Cytokine responses in infants infected with respiratory syncytial virus
}

\author{
Morten Breindahl ${ }^{1,2^{*}}$, Klaus Rieneck ${ }^{2}$, Claus Nielsen², Tage Justesen ${ }^{3}$, Klaus Bendtzen $^{2}$, \\ Klaus Müller ${ }^{2,4}$ \\ ${ }^{1}$ Department of Pediatrics, Hillerod Hospital, Hillerod, Denmark; ${ }^{*}$ Corresponding Author: breindahl@dadlnet.dk \\ ${ }^{2}$ Institute for Inflammation Research (IIR), Department of Rheumatology, Rigshospitalet University Hospital, Copenhagen, Denmark \\ ${ }^{3}$ Department of Clinical Microbiology, Hillerod Hospital, Hillerod, Denmark \\ ${ }^{4}$ Pediatric Clinic II, Rigshospitalet University Hospital, Copenhagen, Denmark
}

Received 19 December 2011; revised 20 January 2012; accepted 2 February 2012

\begin{abstract}
Introduction: Variability in severity of Respiratory Syncytial Virus (RSV) infection is reportedly due to differences in inflammatory response. Objective: To characterize the cytokine response in RSV+ infants aged 0 - 36 months and to relate their responses to disease severity. Methods: Nasopharyngeal aspirations (NPAs) were analyzed for RSV and IL- $1 \beta$, IL-2, IL-4, IL-5, IL-6, IL-10, IL-12, IL-1RA, IL-4R, IFN- $\gamma$, sTNFR1, sTNFR2, and TNF- $\alpha$. Clinical data were collected from the medical records. Results: We included 331 infants of whom 214 were RSV+. In comparison to RSV- infants, they had significantly higher levels of TNF- $\alpha$, IL-6, IL-1 $\beta$, and IFN- $\gamma(p<$ $0.05)$. This also applied to anti-inflammatory cytokine IL-10 levels, but these levels were remarkably lower than levels of TNF- $\alpha$, IL-6, and IL-1 $\beta$. sTNFR1/2 were significantly increased in RSV+ infants. Hospitalized patients had significantly higher levels of TNF- $\alpha$, sTNFR2, and IL-10 $(p<0.05)$ than non-hospitalized patients. The cytokine response could not be related to disease severity. We found no evidence of a skewed Th1/Th2 immune profile. Conclusion: In acute RSV disease, infected infants' NPAs contain a significant amount of pro-inflammatory cytokines. Whether this response is beneficial or deleterious remains unanswered. Interpersonal variations in cytokine responses might be linked to an inherited tendency to variations in disease severity.
\end{abstract}

Keywords: Respiratory Syncytial Virus; Bronchiolitis; Inflammation; Cytokines; Infants Aged 0 - 3 Years

\section{INTRODUCTION}

A number of findings suggest that the variability in the severity of respiratory syncytial virus (RSV) infections may be rooted in individual differences in inflammatory response [1,2] and not to RSV polymorphisms

(http://www.ncbi.nlm.nih.gov/sites/entrez? Db=genome\& Cmd=ShowDetailView\&TermToSearch $=11728$ ).

Ex vivo studies have focused on cytokine production by cord blood cells [3-6] or peripheral blood mononuclear cells [7-9], or they have measured cytokines in serum [10]. The direct clinical applicability of these results, however, remains, questionable since RSV has never been reported to cause a viremic phase.

In vivo human studies of cytokine levels in airway specimens from RSV+ infants indicate a pronounced production of inflammatory and immunoregulating cytokines such as interleukin (IL-)-2, IL-5, IL-6, IL-8, IL-9, IL-10, IL-11, tumor necrosis factor (TNF), Regulated on Activation Normal T-cell Expressed and Secreted (RANTES), and Eosinophil Cationic Protein (ECP) [11-13]. However, the clinical significance has been difficult to ascertain since the majority of these studies report unsystematic measurements of cytokine candidates in small groups of patients. Moreover, only a few studies have included an appropriate control group.

We studied a large cohort of 0 - 36-month-old infants with acute upper and/or lower respiratory tract infection with the purpose of characterizing the magnitude of their disease symptoms during winter seasons. We evaluated the cytokine response in nasal pharyngeal aspirations (NPAs) to characterize the cytokine responses in RSV+ infants compared to RSV- infants, and to relate cytokine levels to disease severity.

\section{MATERIALS AND METHODS}

\subsection{Participants}

\subsubsection{Inclusion Criteria}

Eligible subjects were infants aged 0 - 36 months referred to the Pediatric Emergency Room (PER) at Hillerød Hospital during three consecutive winter seasons (Octo- 
ber-March) from 2000-2003. The children were admitted due to symptoms of acute upper and/or lower respiratory tract infection (URTI/LRTI), i.e. wheezing, increased respiratory rate (RR), asthmatic breathing, rales, crackles, dyspnea, apnea, cyanosis.

\subsubsection{Exclusion Criteria}

We excluded patients undergoing treatment with corticosteroids or agents with possible symptomatic effects on respiratory symptoms, i.e. $\beta 2$-agonists and antibiotics, and patients with recurrent episodes of bacterial pneumonia, chronic inflammatory diseases, immune deficiencies, chromosome aberrations, and congenital cardiopulmonary diseases, e.g. congenital heart disease (CHD) and bronchopulmonary dysplasia (BPD).

\subsubsection{Study Design}

This study was designed as an open, one-center cohort study.

\section{PROCEDURES}

\subsection{Inclusion}

The principal investigator examined all eligible patients within 24 hours after referral to the PER. The following baseline information was collected: Gestational age at time of birth (GA), birth weight (BW), known presence of chronic lung disease (BPD, cystic fibrosis, asthma, etc.), asthmatic bronchitis, atopic disease, disposition to allergy and/or asthma, and duration of respiratory symptoms before referral to the PER.

The physical examination focused on weight (W), height $(\mathrm{H})$, rectal body temperature $(\mathrm{Tp})$, transcutaneous oxygen saturation (SAT) (without supplemental oxygen being provided), skin color, RR, retractions of the chest wall, flaring of alae nasi, and use of accessory muscles during inspiration. C-reactive protein (CRP), $\mathrm{pH}$, partial pressure of oxygen, and carbon dioxide were measured. Decisions on treatment of the included infants, time of discharge, and the need for clinical outpatient follow-up were left at the discretion of the house officer on duty.

After discharge, the following information was extracted from the medical records: date of discharge, length of stay (LOS) in hospital, RSV test result, confirmed positive culture of a representative tracheobronchial aspiration (TBA) or blood, antibiotic treatment, bronchodilators, steroids, supplemental oxygen, nasal continuous positive airway pressure (n-CPAP), mechanical ventilation, and death.

\subsection{Sampling Technique}

NPAs were sampled by introducing a catheter (charriére 08 , Unoplast $\mathrm{A} / \mathrm{S}$, Denmark) attached to a sterile trachea suction unit (Maersk Medical A/S, Denmark) into the nostrils to the nasopharynx and subsequently applying vacuum $\left(25 \mathrm{~cm} \mathrm{H}_{2} \mathrm{O}\right)$ during a 5-second retraction of the catheter. The catheter was flushed into the sterile mucus trap with $2 \mathrm{ml}$ sterile, isotonic sodium chloride, which was immediately placed on ice and transported to our laboratories.

The samples were weighed using a precision scale weight (Mettler Toledo, Dual Range, Precision 0.01g) and centrifuged at $440 \mathrm{~g}$ for 10 minutes at $4{ }^{\circ} \mathrm{C}$. The supernatants were separated from cell pellets by decantation in toto into another sterile tube and briefly homogenized. Aliquots of $250 \mu \mathrm{l}$ of the supernatant were transferred to 5 - 6 sterile cryo tubes (NUNC A/S, Denmark) containing $20 \mu \mathrm{l} 10 \%$ azide, gently turned several times, and immediately frozen at $-80^{\circ} \mathrm{C}$ until final batch-wise cytokine analysis. The pellet was resuspended in $0.5 \mathrm{ml}$ Phosphate-Buffered Saline (PBS) and kept at $4^{\circ} \mathrm{C}$ until RSV examination within less than 12 hours. The analysis was performed by direct immunofluorescence (DIF) staining (Merifluor ${ }^{\circledR}$ RSV, Meridian Bioscience Inc., Cincinnati, Ohio, USA) at the Department of Clinical Microbiology according to the manufacturer's instruction.

\subsection{Analyses of Inflammatory Mediators}

IL-4 and TNF- $\alpha$ (PeliKine Compact ${ }^{\mathrm{TM}}$ kits, CLB, Amsterdam, the Netherlands) and soluble TNF-receptor 1 (sTNFR1) and 2 (sTNFR2) (Quantikine ${ }^{\circledR}$ kits, R\&D Systems, Abingdon, UK) were quantified in accordance with the manufacturers' manuals. The inter- and intra-assay coefficients of variability of all assays were $<10 \%$. All cytokine analyses were carried out in duplicate. The detection limit of the enzyme-linked immunosorbent assays (ELISAs) used ranged from $0.4-3.0 \mathrm{pg} / \mathrm{ml}$.

IL-1 receptor antagonist (IL-1Ra) and sIL-4R were measured in duplicate by an in-house double-sandwich ELISA using monospecific polyclonal antibodies to purified recombinant cytokines. Briefly, immuno-Maxisorp plates (Nunc, Roskilde, Denmark) were coated with protein-A affinity-purified IgG. The plates were blocked with $1 \%$ human serum albumin in PBS. The assays were calibrated with international standards of the respective cytokines (National Institute for Biological Standards and Controls, Potters Bar, Herfordshire, UK). Biotinylated rabbit antibodies were used as detecting antibodies along with streptavidin-peroxidase (Kirkegaard and Perry La., Gaithersburg, MD, USA). Development was carried out with 1,2-phenylenediamine dihydrochloride and measured at $492 \mathrm{~nm}$. The inter- and intra-assay coefficients of variability for the concentration range [15.0 $\mathrm{pg} / \mathrm{mL}-1.0 \mathrm{ng} / \mathrm{mL}$ ] were $<15 \%$.

IL-2, IL-4, IL-5, IL-10, TNF- $\alpha$ and interferon- $\gamma$ (IFN- $\gamma$ ) were quantified in duplicate by use of the Human 
T-helper 1 and 2 (Th1/Th2) Cytokine Cytometric Bead Array kit (Becton Dickinson (BD) Biosciences Pharmingen, San Diego, California, USA) in accordance with the manufacturer's manual.

\subsection{Ethics}

The local ethics committee (1999-1-1) and the Danish Data Management (2000-41-0313) approved the study, and written, informed consent was obtained from the parents of all patients before participation.

\subsection{Statistical Analyses}

Data were computed with SPSS Version 11.5 (SPSS Inc, Chicago, Illinois). The distribution was significantly different from a normal distribution (Kolmogorov-Smirnov with Lilliefors Significance Correction and ShapiroWilk had p-values $<0.001$ ), and consequently non-parametric statistical methods were applied.

The Mann-Whitney U-test was used for two-independent-samples tests of cytokine levels in the following groups: 1) RSV+/RSV-; 2) female/male; and 3) hospitalized/non-hospitalized. Contingency tables were analyzed using Fisher's exact test for calculations involving groups $<5$; otherwise Yates' corrected chi-square was applied. For numeric and non-parametric continuous data, Spearman's rho was calculated.

\section{RESULTS}

\subsection{Description of Cohort}

Figure 1 provides an overview of the 361 screened study patients. We recruited 331 infants of whom 158 (48\%) were girls. Table 1 shows baseline characteristics of the cohort. Episodes of asthmatic bronchitis treated with bronchodilators and/or steroids had been present in $17 \%$ of the infants. Atopic diseases, diagnosed by a physician, were present in $20 \%$, and $49 \%$ were predisposed for such disease, since asthma and/or allergy defined as $\geq$ 1 positive skin provocation test had been diagnosed in first-degree siblings and/or parents.

Physical examination revealed that $49(15 \%)$ of the infants had normal skin color, $83(25 \%)$ had flushing, $192(58 \%)$ had paleness, and $5(1.5 \%)$ had cyanosis of the extremities. Significant subcostal chest wall retractions were present in $258(78 \%), 54(16 \%)$ had none, whereas $17(5 \%)$ had minor localized suprasternal, supraclavicular, or intercostal retractions without involvement of the subcostal tissue.

Only $59(18 \%)$ were immediately discharged as outpatients, whereas $272(83 \%)$ were hospitalized. The hospitalized infants were significantly younger $(p<0.001)$, were generally more premature at birth $(p=0.030)$, and had a lower SAT $(p<0.007)$ and a higher RR $(p=0.034)$ than out-patients (Table 2).

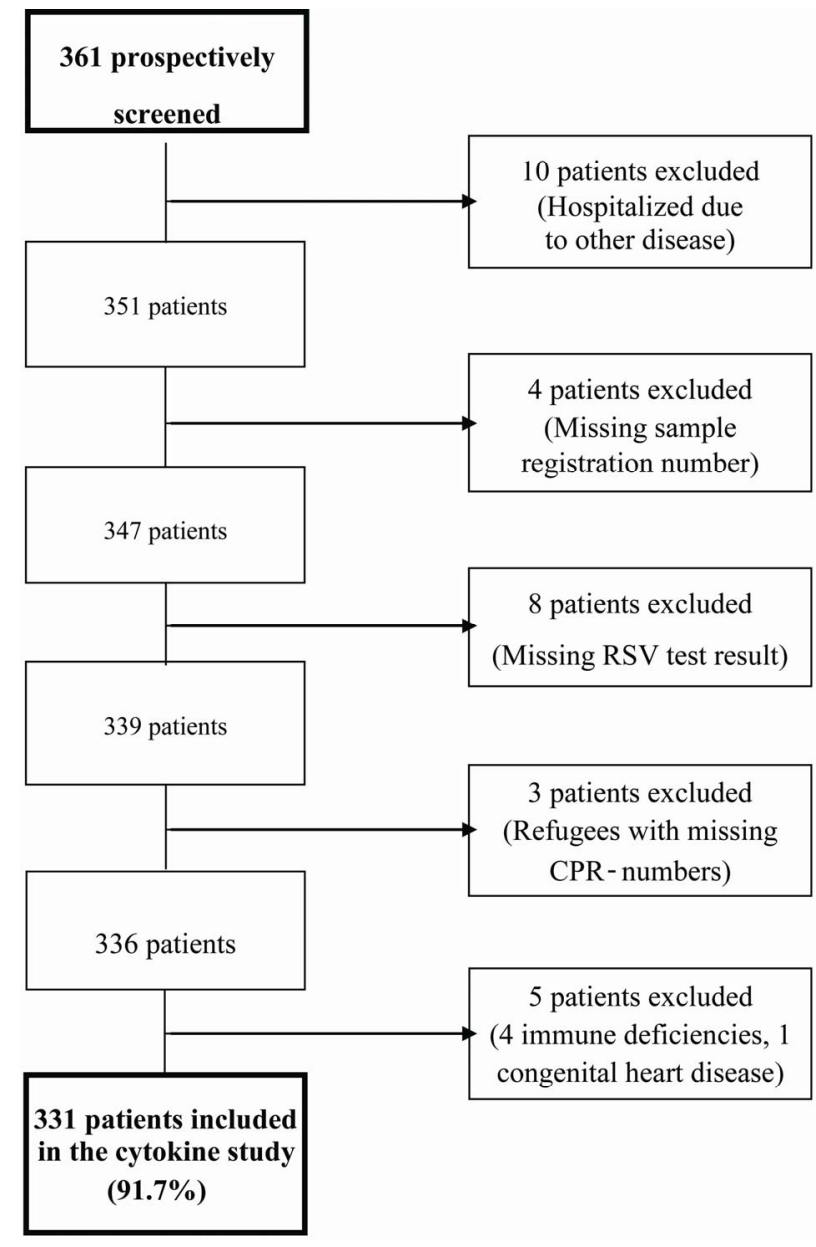

Figure 1. Patient flow chart.

Table 1. Baseline characteristics.

\begin{tabular}{ccc}
\hline Variable & Median & Range \\
\hline Age (weeks) & 17.3 & $1-156$ \\
GA (weeks) & 40 & $28-43$ \\
BW (g) & 3460 & $1-30$ \\
DUR (days) & 5 & \\
Tp ( $\left.{ }^{\circ} \mathbf{C}\right)$ & 37.6 & $35.9-40.6$ \\
SAT (\%) & 94 & $85-100$ \\
RR (n/min) & 52 & $20-100$ \\
\hline
\end{tabular}

Baseline characteristics of the total cohort showing median and range. Please refer to list of abbreviations. 
Almost $2 / 3(65 \%, n=214)$ of the included infants $(n=331)$ were RSV+, while the remaining 117 (35\%) were RSV-.

$\mathrm{RSV}+$ infants were significantly younger than RSVinfants, had increased RR upon admission, and were hospitalized longer (Table 3). However, we found no significant differences between RSV+ and RSV- infants in terms of clinical or paraclinical parameters (i.e., GA, $\mathrm{BW}$, duration of symptoms before referral, Tp, SAT, Creactive protein [CRP], $\mathrm{pH}$, or partial pressure of either oxygen $\left[\mathrm{pO}_{2}\right]$ or carbon dioxide $\left.\left[\mathrm{pCO}_{2}\right]\right)$. Males and females did not differ from each other (data not shown).

Nearly all of the hospitalized infants $(97 \%, 263 / 272)$ received inhalations with bronchodilators, 17\% (45/272) were treated with corticosteroids, and 11\% (31/272) had additional fluid administered either intravenously or orally through a nasogastric tube. Hospitalized infants treated with n-CPAP $(18 \%, 50 / 272)$ had significantly lower age, longer LOS, and higher RR compared to nonn-CPAP-treated infants (not shown). They also had significantly lower GA and BW. At the time of n-CPAP treatment, they had respiratory acidosis with lower $\mathrm{pH}$ and higher $\mathrm{pCO}_{2}$ values than non-hospitalized patients (data not shown). None of the patients died during hospitalization.

Table 2. Characteristics of hospitalized and non-hospitalized.

\begin{tabular}{lccccc}
\hline & \multicolumn{2}{c}{ Hospitalized $(\mathbf{n}=\mathbf{2 7 2})$} & \multicolumn{2}{c}{ Non-hospitalized $(\mathbf{n}=\mathbf{5 9})$} & \multirow{2}{*}{ p value } \\
\cline { 2 - 5 } Variable & Median & Range & Median & Range & \\
\hline Age (weeks) & 15 & $1-149$ & 38 & $4-156$ & $<\mathbf{0 . 0 0 1}$ \\
GA (weeks) & 40 & $28-43$ & 40 & $36-42$ & $\mathbf{0 . 0 3 0}$ \\
BW (g) & 3460 & $835-5500$ & 3453 & $2340-4770$ & 0.428 \\
DUR (days) & 4 & $1-30$ & 4 & $1-30$ & 0.509 \\
Tp ( $\left.{ }^{\circ} \mathbf{C}\right)$ & 37.6 & $35.9-40.6$ & 37.6 & $36.1-40.1$ & 0.840 \\
SAT (\%) & 94 & $85-100$ & 97 & $88-100$ & $\mathbf{0 . 0 0 7}$ \\
RR (n/min) & 52 & $28-100$ & 48 & $20-90$ & 0.34 \\
\hline
\end{tabular}

Non-parametric analyses (Mann-Whitney U-test) of the two independent variables (hospitalized and non-hospitalized), showing median, range, and subsequent p-values. Significant differences highlighted with bold typing. Please refer to list of abbreviations.

Table 3. Characteristics of RSV+ and RSV-.

\begin{tabular}{lccccc}
\hline \multirow{2}{*}{ Variable } & \multicolumn{2}{c}{$\mathbf{R S V}+(\mathbf{n}=\mathbf{2 1 4})$} & \multicolumn{2}{c}{$\mathbf{R S V}-(\mathbf{n}=\mathbf{1 1 7})$} & \multirow{2}{*}{ p values } \\
\cline { 2 - 4 } & Median & Range & Median & Range & \\
\hline Age (weeks) & 15 & $1-149$ & 25 & $1-156$ & $\mathbf{0 . 0 0 2}$ \\
GA (weeks) & 40 & $28-42$ & 40 & $32-43$ & 0.159 \\
BW (g) & 3420 & $835-5500$ & 3560 & $1580-5200$ & 0.091 \\
DUR (days) & 5 & $1-14$ & 5 & $1-30$ & 0.573 \\
LOS (days) & 3 & $0-27$ & 1 & $0-12$ & $<\mathbf{0 . 0 0 1}$ \\
Tp ( $\left.{ }^{\circ} \mathbf{C}\right)$ & 37.6 & $35.9-40.6$ & 37.5 & $36.1-40.4$ & 0.283 \\
SAT (\%) & 94 & $86-100$ & 95 & $85-100$ & 0.550 \\
RR (n/min) & 52 & $28-100$ & 48 & $20-90$ & $\mathbf{0 . 0 0 7}$ \\
$\mathbf{C R P}(\mathbf{n g} / \mathbf{m l})$ & 129 & $1-2388$ & 112 & $1-1392$ & 0.929 \\
$\mathbf{p H}$ & 7.37 & $7.25-7.45$ & 7.36 & $7.12-7.45$ & 0.314 \\
$\mathbf{p O}$ & 6.40 & $3.50-12.30$ & 7.35 & $4.30-10.50$ & 0.224 \\
$\mathbf{p C O}$ & 5.90 & $4.40-9.30$ & 5.90 & $4.10-13.40$ & 0.793 \\
\hline
\end{tabular}

Non-parametric analyses (Mann-Whitney U-test) of the two independent variables (RSV+ and RSV-infants) showing median, range, and subsequent p-values. Significant differences highlighted with bold typing. Please refer to list of abbreviations. 


\subsection{Analyses of Cytokines in Nasopharyngeal Aspirations}

The nasopharyngeal aspirates from RSV+ infants contained significantly higher levels of the pro-inflammatory mediators TNF- $\alpha$, IL-6, IL-1 $\beta$, and IFN $\gamma$ (Figures 2(a)(d)) than those of RSV- infants. Though the same applied to the levels of the anti-inflammatory cytokine IL-10 (Figure 2(e)), the IL-10 levels were remarkably lower than those of TNF- $\alpha$, IL- 6 and IL- $1 \beta$.

We also measured the levels of sTNFR1 and sTNFR2, which correlated significantly in 35 randomly selected patients (Spearman's rho 0.950, $\mathrm{p}<0.001$, not shown). We therefore proceeded with in-depth analyses of sTNFR2 only. The levels of this receptor were also increased in RSV+ infants (Figure 2(f)).

The levels of TNF- $\alpha$, sTNFR2, and IL-10 (Figures 3(a)-(c)) were higher in hospitalized infants than in out-patients. This was not the case for the other cytokines tested (data not shown).

No significant differences in cytokine levels were found upon subgroup analysis of the cohort stratified into 1) age groups: young infants: $0-2$ months, infants: $3-11$ months, and young children: 12 - 36 months; 2) n-CPAP treatment: n-CPAP+, n-CPAP-; 3) bacterial contamination in TBA; 4) degree of retractions: suprasternal, supraclavicular, intercostal, subcostal; or 5) scoring of skin color: normal, flushing, paleness, cyanosis (not shown).

\subsection{Th1/Th2-Related Cytokines}

To further characterize the Th1/Th2 profile of the cy-tokines in NPAs, we made a computerized random selection of approximately 60 samples to be tested for IL-2, IL-4, IL-5, IL-12, and sIL-4R.

The measured levels were either very low (maximum

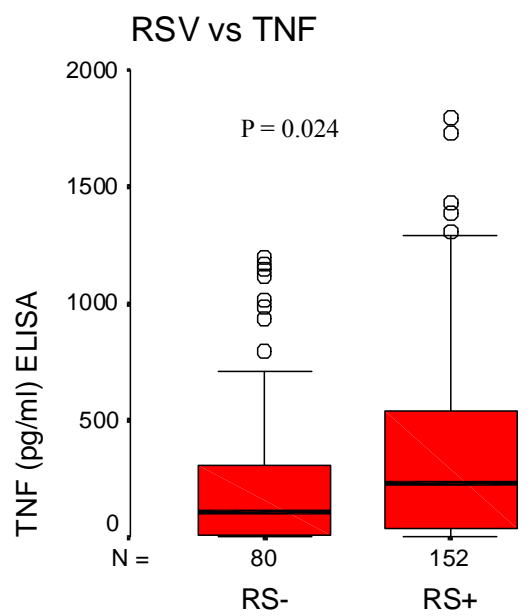

(a)

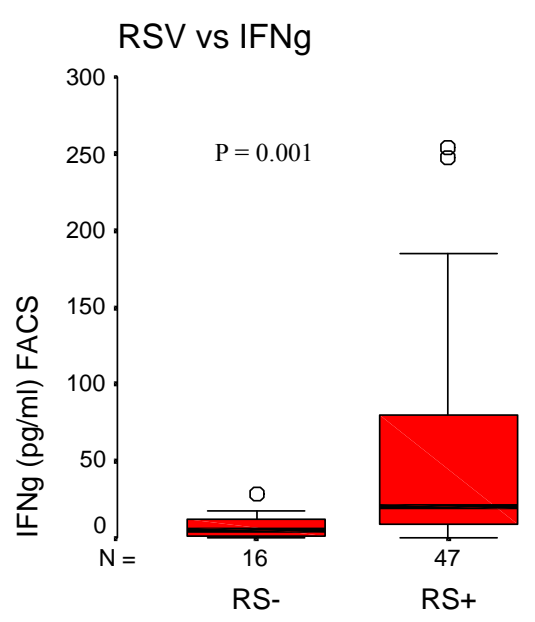

(d)

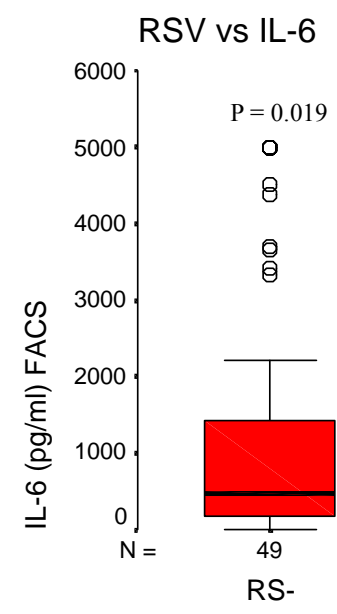

(b)

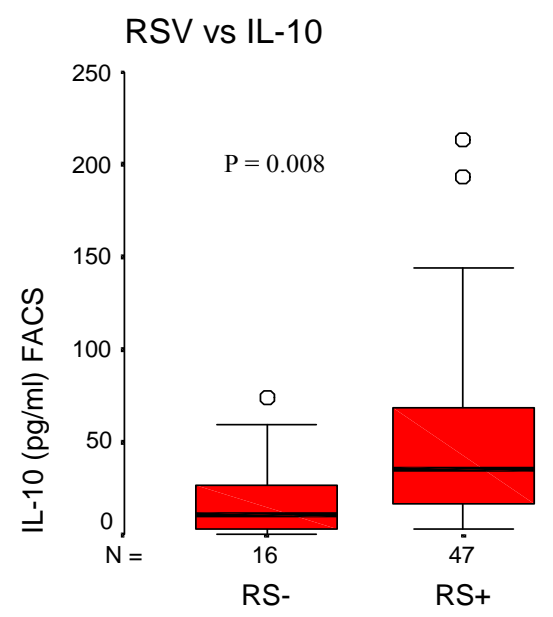

(e)

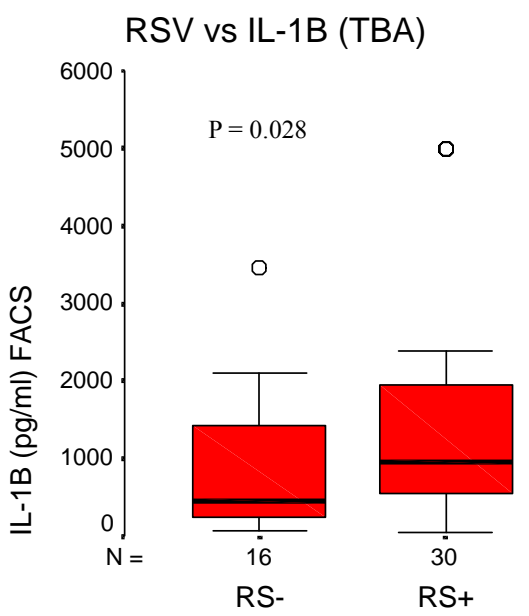

(c)

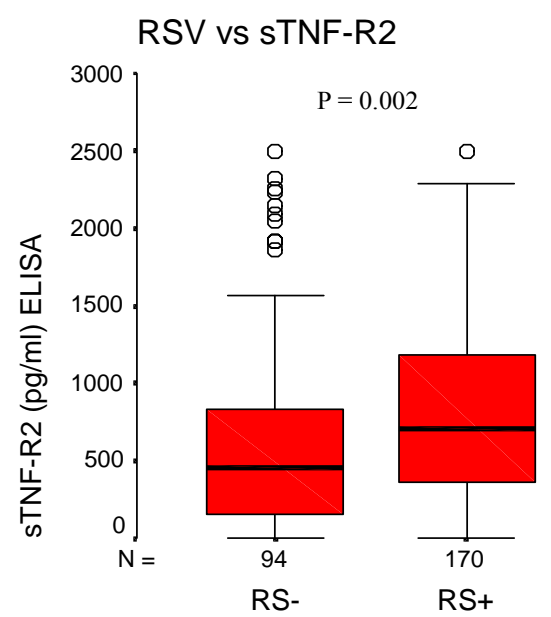

(f)

Figure 2. Boxplots showing RSV+ and RSV- infants versus the levels of (a) TNF- $\alpha$; (b) IL-6; (c) IL-1 $\beta$; (D) IFN- $\gamma$; (e) IL-10 and (f) sTNFR2. Non-parametric analyses by Mann-Whitney U-test show significant differences between RSV+ and RSV- infants $(\mathrm{p}<$ $0.05)$. 


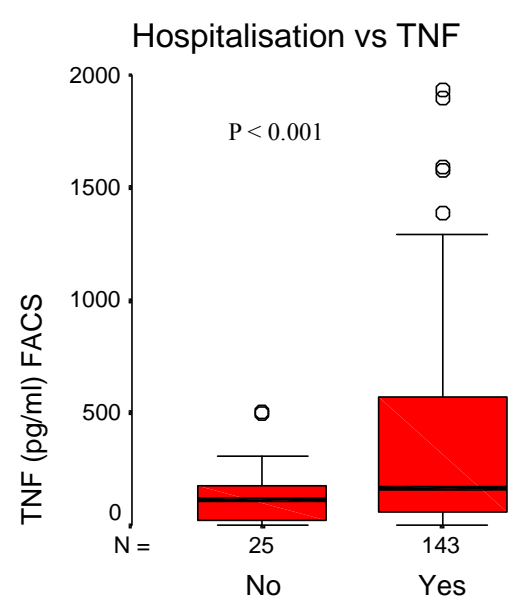

(a)

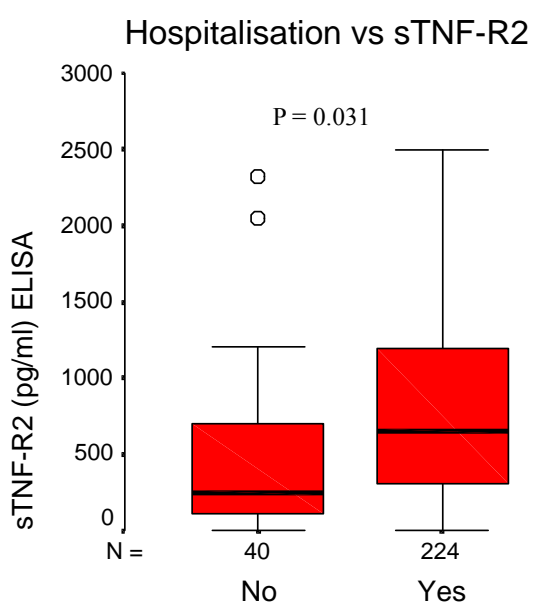

(b)

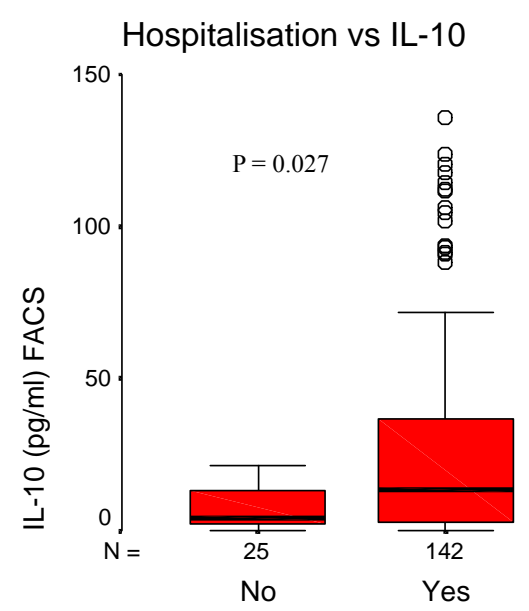

(c)

Figure 3. Boxplots showing hospitalized and non-hospitalized infants versus the levels of (a) TNF- $\alpha$; (b) sTNFR2 and (c) IL-10. Non-parametric analyses by Mann-Whitney U-test show significant differences between hospitalized and non-hospitalized $(\mathrm{p}<0.05)$.

concentrations of IL-12 $<70 \mathrm{pg} / \mathrm{ml}$ ) or below detectable thresholds (IL-2, IL-4, IL-5, and sIL-4R).

\subsection{Cytokine Profile versus Severity of Disease}

We performed statistical analysis of subgroups of the study cohort divided into 1) eligible RSV+ patients, aged 0 - 6 months and 2) eligible RSV+ patients, aged 0 - 3 months, in order to spot possible deviations in cytokine profile as reflected by their disease severity. We found no statistically significant differences in either subgroup when correlating with the measured cytokines between infants with 1 ) very short ( $\leq 1$ day) vs long ( $\geq 2$ days) hospitalization; 2) short ( $\leq 2$ days) vs long ( $\geq 3$ days) hospitalization; 3) normocapnia vs hypercapnia; or 4) with no need for respiratory support (-n-CPAP) vs need for respiratory support (+n-CPAP) (data not shown).

\section{DISCUSSION}

We examined a large group of infants with acute respiratory distress referred to the PER for immediate pediatric evaluation during three winter seasons in Denmark.

Most infants had been ill for approximately one week upon referral. Hospitalized infants constituted almost $83 \%$. Compared to the non-hospitalized group, they were younger and had clinical symptoms indicating more severe disease, e.g. lower SAT and higher RR. The majority of these infants were RSV+ and they were significantly younger than the RSV- infants, which is in line with the notion that RSV infection results in more serious illness at younger age [14].

Apart from younger age, other well-known risk factors include prematurity, congenital heart disease, lung disease, and immunodeficiency. However, it has been difficult to identify reliable prognostic factors for development of severe disease in previously healthy infants [15].
A number of cytokine gene polymorphisms may be associated with severe RSV disease, and high levels of inflammatory cytokines in RSV-infected infants have previously been demonstrated in both acute URTI [16] and RSV-related bronchiolitis [17]. However, it has not been thoroughly investigated whether the degree of inflammation, as measured by the levels of these mediators, predicts the clinical course of the disease. Specific cytokine profiles associated with RSV-infection have not been reported. In general, it has not been shown whether the inflammatory response seen upon RSV infection differs from the response to other viruses, and whether this reaction is beneficial or deleterious [18]. In fact, the immaturity of the infant immune system may alter the outcome of this viral infection, but at the same time, the viral infection possibly shapes the development of the infant's immune system and its future responses [19].

In our cohort, we found a predominantly pro-inflamematory cytokine response in NPAs from RSV+ infants that was significantly different from that found in RSVinfants. In particular, TNF- $\alpha$, IL- 6 , and IL- $1 \beta$ were found at concentrations likely to be of pathogenic importance. These findings are consistent with the previous observation that RSV binding to Toll-like receptor (TLR)-4 in airway epithelium may result in release of pro-inflamematory cytokines through activation of nuclear factorkappa B [20], which controls the expression of numerous RSV-inducible inflammatory and immunomodulatory genes. However, multiple TLRs activate the innate immune system upon RSV infection, and though TLR activation may cause a specific cytokine production, viral factors may well counteract these pathways, thereby contributing to RSV proliferation [21].

Despite the finding of elevated concentrations of inflammatory cytokines in RSV+ infants along with the observation that these infants needed longer hospitalize- 
tion than RSV- infants, we were unable to demonstrate any direct correlation between the level of inflammatory cytokines and the severity of pulmonary symptom scores.

Due to the association between the development of asthma and severe RSV infection, researchers have speculated whether the immune response elicited upon RSV is a Th2-predominant phenotype. Though animal models have indicated a skewed Th1/Th2 cytokine balance in RSV-related disease, this observation has not yet been systematically confirmed in humans [22,23]. An excess type 2 immune response during RSV bronchiolitis has been suggested based on ratios of Th1- and Th2-related cytokines from nasal lavage fluid and stimulated PBMC [22]. Similarly, Th2 responses have been detected in NPA from children during viral lower respiratory tract infection, but these responses were not unique for RSV infection [24].

We found very low levels of Th1- and Th2-related cytokines. Even though the concentrations of IFN- $\gamma$ and IL-10 were significantly higher in RSV+ than in RSVinfants, they were so low that a biological effect must be doubtful. IL-10 is known to down-regulate pro-inflamematory and to upregulate anti-inflammatory mediators including the shedding of sTNFR2. This soluble receptor has a dual action, since it serves as an effective inhibitor of ligand activity (here: TNF- $\alpha$ ) at high concentrations, and acts as a facilitator of ligand-binding at low concentrations. To our knowledge, the present study is the first to show sTNFR2 in infants with RSV infection. Although the levels were significantly higher in RSV+ infants, they were within the lower range of that seen in sera of healthy children and in children with inflammatory conditions $[25,26]$. Along with the fact that TNF concentrations were highly elevated in the airway secretion, this suggests that at the levels found here sTNFR2 is unlikely to effectively suppress TNF- $\alpha$ activity in the airway secretion of these patients. On the contrary, one may speculate that the sTNFR2 levels may facilitate TNF- $\alpha$ activity in airway secretion. We were unable to further substantiate this, since the ratio of TNF- $\alpha$ to sTNFR2 did not correlate with the clinical severity of disease.

During the acute phase, RSV infection seems to be characterized by a predominantly pro-inflammatory immune response. We demonstrated no association between the level of pro-inflammatory cytokines and the clinical severity of the infection. However, the cytokines observed in airway secretions from these patients may be involved in the pathogenesis of RSV-associated bronchiolitis - or they may represent an appropriate defense mechanism against the viral infection. Thus, it remains unanswered whether the cytokines measured are to be considered "friend" or "foe".

In conclusion, this large-scale prospective study of pa- tients aged 0 - 36 months with symptoms of URTI/LRTI provides evidence of a predominantly pro-inflammatory cytokine response in RSV+ infants significantly different from that encountered in RSV- infants. RSV+ infants also had significantly higher concentrations of sTNFR2, a finding not previously reported. However, the data do not suggest that cytokine profiling of airway secretions can be used as a prognostic tool for determining the risk of developing severe disease manifestations in a clinical setting.

\section{CONTRIBUTORS}

M. Breindahl and K. Müller wrote the study protocol. M. Breindahl was responsible for the planning of the study, collected all data and processed all samples, did the statistical analyses and wrote the first draft of this manuscript. He supervised and held responsibility for all laboratory analyses, of which he conducted a significant part himself. K. Müller supervised the study, and he, K. Bendtzen, K. Rieneck, C. H. Nielsen, and T. Justesen revised and approved all drafts of this manuscript. Lone Bredahl and Marianne Thomsen performed the majority of cytokine analyses at the Institute for Inflammation Research. T. Justesen and the technical staff at the Department of Clinical Microbiology, Hillerød Hospital, conducted the RSV tests.

\section{ACKNOWLEDGEMENTS}

Funding has been granted from the Medical Research Foundation in Region III, East-Danish Medical Research Forum (ØSFF), Frederiksborg County Research Foundation, Rosalie Petersen's Foundation, Captain Harald Jensen and Wife's Foundation, Mrs Olga Bryde Nielsen's Foundation, Tvergaard Foundation, the Danish Medical Association's Research Foundation, the Danish Pediatric Society (DPS). K. Bendtzen provided additional funding through applications to the Lundbeck Foundation and the Danish Biotechnology Program. We would also like to thank the parents of the included infants for their willingness to let their acutely ill children participate in this study.

\section{REFERENCES}

[1] Garofalo, R.P., Patti, J., Hintz, K.A., Hill, V., Ogra, P.L. and Welliver, R.C. (2001). Macrophage inflammatory protein-1alpha (not $\mathrm{T}$ helper type 2 cytokines) is associated with severe forms of respiratory syncytial virus bronchiolitis. The Journal of Infectious Diseases, 184, 393-399. doi: $10.1086 / 322788$

[2] McNamara, P.S., Flanagan, B.F., Baldwin, L.M., Newland, P., Hart C.A. and Smyth, R.L. (2004). Interleukin 9 production in the lungs of infants with severe respiratory syncytial virus bronchiolitis. The Lancet, 363, 1031-1037. doi:10.1016/S0140-6736(04)15838-8

[3] Juntti, H., Osterlund, P., Kokkonen, J., Dunder, T., Renko, Pokka, M.T., Julkunen, I. and Uhari, M. (2009) Cytokine 
responses in cord blood predict the severity of later respiratory syncytial virus infection. The Journal of Allergy and Clinical Immunology, 124, 52-58.

doi:10.1016/j.jaci.2009.04.014

[4] Gern, J.E., Brooks, G.D., Meyer, P., Chang, A., Shen, K., Evans, M.D., Tisler, C., Dasilva, D., Roberg, K.A., Mikus, L.D., Rosenthal, L.A., Kirk, C.J., Shult, P.A. Bhattacharya, A., Li, Z., Gangnon, R. and Lemanske, R.F. Jr. (2006) Bidirectional interactions between viral respiratory illnesses and cytokine responses in the first year of life. The Journal of Allergy and Clinical Immunology, 117, 72-78. doi:10.1016/j.jaci.2005.10.002

[5] Copenhaver, C.C., Gern, J.E., Li, Z., Shult, P.A., Rosenthal, L.A., Mikus, L.D., Kirk, C.J., Roberg, K.A., Anderson, E.L., Tisler, C.J., DaSilva, D.F., Hiemke, H.J., Gentile, K., Gangnon, R.E. and Lemanske, R.F. Jr. (2004) Cytokine response patterns, exposure to viruses, and respiratory infections in the first year of life. American Journal of Respiratory and Critical Care Medicine, 170, 175-180. doi:10.1164/rccm.200312-1647OC

[6] Krishnan, S., Craven, M., Welliver, R.C., Ahmad, N. and Halonen, M. (2003). Differences in participation of innate and adaptive immunity to respiratory syncytial virus in adults and neonates. The Journal of Infectious Diseases, 188, 433-439. doi: $10.1086 / 376530$

[7] Castro, M., Schweiger, T., Yin-Declue, H., Ramkumar, T.P., Christie, C., Zheng, J., Cohen, R., Schechtman, K.B., Strunk, R. and Bacharier, L.B. (2008) Cytokine response after severe respiratory syncytial virus bronchiolitis in early life. The Journal of Allergy and Clinical Immunology, 122, 726-733. doi:10.1016/j.jaci.2008.07.010

[8] Anderson, L.J., Tsou, C., Potter, C., Keyserling, H.L., Smith, T.F., Ananaba, G. and Bangham, C.R. (1994) Cytokine response to respiratory syncytial virus stimulation of human peripheral blood mononuclear cells. The Journal of Infectious Diseases, 170, 1201-1208. doi:10.1093/infdis/170.5.1201

[9] Tripp, R. A., Moore, D., Barskey, A., Jones, L., Moscatiello, C., Keyserling, H. and Anderson, L.J. (2002) Peripheral blood mononuclear cells from infants hospitalized because of respiratory syncytial virus infection express T helper-1 and T helper- 2 cytokines and CC chemokine messenger RNA. The Journal of Infectious Diseases, 185, 1388-1394. doi:10.1086/340505

[10] Fernandez, J.A., Tapia, L., Palomino, M.A., Larranaga, C., Pena, M. and Jaramillo, H. (2005) Plasma interferon-gamma, interleukin-10 and soluble markers of immune activation in infants with primary adenovirus (ADV) and respiratory syncytial virus (RSV) infection. European Cytokine Network, 16, 35-40.

[11] Welliver, T.P., Garofalo, R.P., Hosakote, Y., Hintz, K.H., Avendano, L., Sanchez, K., Velozo, L., Jafri, H., ChavezBueno, S., Ogra, P.L., McKinney, L., Reed, J.L. and Welliver, R.C. Sr. (2007) Severe human lower respiratory tract illness caused by respiratory syncytial virus and influenza virus is characterized by the absence of pulmonary cytotoxic lymphocyte responses. The Journal of Infectious Diseases, 195, 1126-1136. doi:10.1086/512615

[12] Bont, L., Heijnen, C.J., Kavelaars, A., van Aalderen, W.M., Brus, F., Draaisma, J.M., Pekelharing-Berghuis, M., van
Diemen-Steenvoorde, R.A. and Kimpen, J.L. (2001) Local interferon-gamma levels during respiratory syncytial virus lower respiratory tract infection are associated with disease severity. The Journal of Infectious Diseases, 184, 355-358. doi:10.1086/322035

[13] Joshi, P., Kakakios, A., Jayasekera, J. and Isaacs, D. (1998) A comparison of IL-2 levels in nasopharyngeal and endotracheal aspirates of babies with respiratory syncytial viral bronchiolitis. The Journal of Allergy and Clinical Immunology, 102, 618-620. doi:10.1016/S0091-6749(98)70278-7

[14] Shaw, K.N., Bell, L.M. and Sherman, N.H. (1991) Outpatient assessment of infants with bronchiolitis. Archives of Pediatrics \& Adolescent Medicine, 145, 151-155.

[15] Willson, D.F., Horn, S.D., Hendley, J.O., Smout, R. and Gassaway, J. (2001) Effect of practice variation on resource utilization in infants hospitalized for viral lower respiratory illness. Pediatrics, 108, 851-855. doi:10.1542/peds.108.4.851

[16] Noah, T.L., Henderson, F.W., Wortman, I.A., Devlin, R.B., Handy, J., Koren, H.S. and Becker, S. (1995) Nasal cytokine production in viral acute upper respiratory infection of childhood. Journal of Infectious Diseases, 171, 584-592. doi:10.1093/infdis/171.3.584

[17] Bennett, B.L., Garofalo, R.P. Cron, S.G. Hosakote, Y.M. Atmar, R.L. Macias, C.G. and Piedra, P.A. (2007) Immunopathogenesis of respiratory syncytial virus bronchiolitis. The Journal of Infectious Diseases, 195, 1532-1540. doi:10.1086/515575

[18] Welliver, T.P., Garofalo, R.P., Hosakote, Y., Hintz, K.H., Avendano, L., Sanchez, K., Velozo, L., Jafri, H., ChavezBueno, S., Ogra, P.L., McKinney, L., Reed, J.L. and Welliver, R.C. Sr. (2007) Severe human lower respiratory tract illness caused by respiratory syncytial virus and influenza virus is characterized by the absence of pulmonary cytotoxic lymphocyte responses. The Journal of Infectious Diseases, 195, 1126-1136. doi:10.1086/512615

[19] Tregoning, J.S. and Schwarze, J. (2010) Respiratory viral infections in infants: Causes, clinical symptoms, virology, and immunology. Clinical Microbiology Reviews, 23, 7498. doi:10.1128/CMR.00032-09

[20] Haeberle, H.A., Takizawa, R., Casola, A., Brasier, A.R., Dieterich, H.J., Van, R.N., Gatalica, Z. and Garofalo, R.P. (2002) Respiratory syncytial virus-induced activation of nuclear factor-kappaB in the lung involves alveolar macrophages and toll-like receptor 4-dependent pathways. The Journal of Infectious Diseases, 186, 1199-1206. doi:10.1086/344644

[21] Klein, K.P., Tan, L., Werkman, W., van Bleek, G.M. and Coenjaerts, F. (2009) The role of Toll-like receptors in regulating the immune response against respiratory syncytial virus. Critical Reviews in Immunology, 29, 531-550.

[22] Legg, J.P., Hussain, I.R., Warner, J.A., Johnston, S.L. and Warner, J.O. (2003) Type 1 and type 2 cytokine imbalance in acute respiratory syncytial virus bronchiolitis. American Journal of Respiratory and Critical Care Medicine, 168, 633-639. doi:10.1164/rccm.200210-1148OC

[23] Garofalo, R.P., Patti, J., Hintz, K.A., Hill, V.P., Ogra, L. and Welliver, R.C. (2001) Macrophage inflammatory pro- 
tein-1alpha (not $\mathrm{T}$ helper type 2 cytokines) is associated with severe forms of respiratory syncytial virus bronchiolitis. The Journal of Infectious Diseases, 184, 393-399. doi:10.1086/322788

[24] Byeon, J.H., Lee, J.C., Choi, I.S., Yoo, Y., Park, S.H. and Choung, J.T. (2009) Comparison of cytokine responses in nasopharyngeal aspirates from children with viral lower respiratory tract infections. Acta Paediatrica, 98, 725-730. doi:10.1111/j.1651-2227.2008.01208.x

[25] Bjornhart, B., Svenningsen, P., Gudbrandsdottir, S., Zak,
M., Nielsen, S., Bendtzen, K. and Muller, K. (2005) Plasma TNF binding capacity in patients with juvenile idiopathic arthritis. International Immunopharmacology, $\mathbf{5}$. 73-77. doi:10.1016/j.intimp.2004.09.022

[26] Andersen, J., Heilmann, C., Jacobsen, N., Nielsen, C., Bendtzen, K. and Muller, K. (2006) Differential effect of conditioning regimens on cytokine responses during allogeneic stem cell transplantation. Bone Marrow Transplantation, 37, 635-640. doi:10.1038/sj.bmt.1705295

\section{Abbreviations}

\begin{tabular}{|c|c|c|c|}
\hline BPD & Bronchopulmonary Dysplasia & PBS & Phosphate-Buttered Saline \\
\hline BW & Birth Weight & PER & Pediatric Emergency Room \\
\hline $\mathrm{CF}$ & Cystic Fibrosis & $\mathrm{RR}$ & Respiratory Rate \\
\hline $\mathrm{CHD}$ & Congenital Heart Disease & RSV & Respiratory Syncytial Virus \\
\hline DUR & $\begin{array}{l}\text { Duration of illness before referral to } \\
\text { PER }\end{array}$ & RSV- & $\begin{array}{l}\text { Respiratory Syncytial Virus negative } \\
\text { (patients) }\end{array}$ \\
\hline GA & Gestational Age & RSV+ & Respiratory Syncytial Virus positive (patients) \\
\hline $\mathrm{H}$ & Height & SAT & Transcutaneous Oxygen Saturation \\
\hline IFN- $\gamma$ & Interferon-gamma & sIL4-R & Soluble Interleukin 4 Receptor \\
\hline IIR & Institute for Inflammation Research & sTNFR $1 / 2$ & $\begin{array}{l}\text { Soluble Tumor Necrosis Factor Receptor } \\
1 \text { and } 2\end{array}$ \\
\hline IL & Interleukin & TBA & Tracheo-Bronchial Aspiration \\
\hline IL-1-Ra & Interleukin 1 Receptor Antagonist & Th1/Th2 & T-Helper cell type 1 and 2 \\
\hline LOS & Length of Stay & TLR & Toll-Like Receptor \\
\hline LRTI & Lower Respiratory Tract Infection & $\mathrm{TNF}-\alpha$ & Tumor Necrosis Factor Alfa \\
\hline n-CPAP & $\begin{array}{l}\text { Nasal Continuous Positive Airway } \\
\text { Pressure }\end{array}$ & $\mathrm{Tp}$ & Temperature \\
\hline JPA & Nasopharyngeal Aspiration & URTI & Upper Respiratory Tract Infection \\
\hline $3 \mathrm{MC}$ & Peripheral Blood Mononuclear Cells & $\mathrm{W}$ & Weight \\
\hline
\end{tabular}

